\title{
ALGO MÁS ACERCA DEL «COTO VEDADO»
}

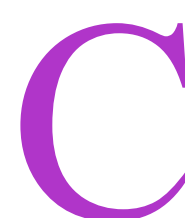

on «telegráfica brevedad», pero no por ello sin agudo espíritu crítico, Javier de Lucas ha formulado observaciones a mi trabajo sobre la democracia representativa. Procuraré responderlas también breve y convincentemente. Dos son los aspectos centrales puestos en tela de juicio: a) el contenido y alcance del «coto vedado» y b) la posibilidad de incluir a Kelsen como partidario del «coto vedado».

a) En mi trabajo he sostenido la existencia de una vinculación conceptual entre democracia representativa y «coto vedado». Esta vinculación es válida si se acepta que la democracia representativa no significa el «dominio de la mayoría» sino la vigencia del «principio de la mayoría», dentro de un marco de homogeneidad social que permita alentar la esperanza de la autodeterminación individual.

Los derechos incluidos en el «coto vedado» son aquellos vinculados con la satisfacción de los bienes básicos, es decir, que son condición necesaria para la realización de cualquier plan de vida. Estos bienes básicos pueden ser llamados también «necesidades básicas», en su doble versión de naturales o derivadas. Un ejemplo de necesidad básica natural es el comer o el contar con vivienda y vestido para protegerse de las inclemencias del clima. Una necesidad básica derivada es, en nuestras sociedades, el saber leer y escribir y estar vestido con un mínimo de decencia. Mientras las necesidades básicas naturales son las mismas en todas las sociedades, las derivadas cambian según los tiempos y las sociedades. Tienen, además, una tendencia a la expansión. Javier de Lucas plantea la pregunta de cómo se conocen los derechos que deben ser incluidos en el «coto vedado»y cómo se los introducen en el mismo. Esto equivale a preguntarse cómo se conocen los derechos fundamentales que están incluidos en prácticamente todas las Constituciones democráticas. Si el término «conocer» significa tan sólo enterarse de su existencia universalmente aceptada, una vía sumamente fácil es recurrir al catálogo 
de derechos humanos incluidos en las declaraciones de las Naciones Unidas y aprobados por todos los Estados del mundo. Si «conocer» significa «fundamentar» o «justificar», nos encontramos con un problema de ética normativa que puede ser solucionado sin necesidad de recurrir a fundamentaciones metafísicas o teológicas. Basta pensar en las propuestas del objetivismo ético, tales como las presentadas por James S. Fishkin (Beyond Subjective Morality - Ethical Reasoning and Political Philosophy, Yale University Press, New Haven/Londres, 1984) o por Mario Bunge (Treatise on Basic Philosophy, vol. 8 [The Good and the Right], D. Reidel Publishing Company, Dordrecht/Boston/Lancaster, 1989). Quien introduce este catálogo de derechos en el «coto vedado» suele ser la asamblea constituyente, el primer legislador, si es que está interesado en el establecimiento de una democracia representativa. Pero como las necesidades básicas derivadas tienen una tendencia a la expansión, es probable que con el transcurso del tiempo haya que introducir nuevos elementos en la clase de los derechos del «coto vedado», si se quiere mantener la homogeneidad social en el sentido definido en mi trabajo. Los derechos humanos de la segunda o tercera generación, suelen estar vinculados con esta tendencia expansionista de las necesidades básicas derivadas. No se trata aquí de derechos sustancialmente diferentes a los de la primera generación, sino que tienen la misma jerarquía. Por ello deben ser incluidos en el «coto vedado».

Si la mayoría se opone a su introducción tendrá que demostrar que estos nuevos derechos no responden a necesidades básicas derivadas o que su introducción es redundante. Si tal no fuera el caso habría buenas razones para pensar que la mayoría aspira tan sólo a ejercer su dominación y no tiene interés en respetar el «principio de la mayoría» o, lo que es lo mismo, la democracia representativa.

Los derechos incluidos en el «coto vedado» valen, desde luego, prima facie. Como señalo en la última parte de mi trabajo, pueden presentarse conflictos debido a que o bien no es posible la satisfacción simultánea de dos o más derechos básicos o bien se carece de recursos económicos suficientes. En ambos casos, la carga de la prueba de que tal es el caso corre por cuenta de quien se oponga a la satisfacción de estos derechos. Por las razones expuestas al final de mi trabajo, creo que esta exigencia no es trivial. Dicho con otras palabras: si se quiere hablar de «producción normativa» con relación al «coto vedado», ella debe ser entendida primordialmente en el sentido de la realización efectiva de los derechos incluidos en él y -si esto fuera circunstancialmente 
Imposible- de su suspensión o reducción transitorias, de acuerdo con el principio de la carga de la prueba.

Me da la impresión de que javier de lucas me reprocha suavemente un exceso de paternalismo por lo que respecta a la satisfacción de los deseos secundarios de los representados, ya que yo habría sostenido que ellos no deberían «ser formulados expresamente, sino supuestos racionalmente por los representantes desde un consentimiento hipotético de los representados». Esta no es, por cierto, mi posición: no he afirmado que los deseos secundarios de los representados no deban ser respetados sino que tan sólo me he limitado a introducir una cláusula cautelar basada en la mayor información de que normalmente dispone el representante y que, por su propia calidad de tal, tiene que tomar en cuenta para dar satisfacción cabal de los deseos de los representados. Una obligación incondicionada de satisfacer los deseos secundarios de representados mal o deficientemente informados podría conducir a situaciones realmente catastróficas poniendo en peligro hasta los deseos primarios de la gente. javier de lucas posiblemente recordaría aquí el deber de información, propio de todo gobierno democrático. Ello es correcto, pero siempre el representante tendría el plus de información que le concede el hecho de su participación directa en la negociación que conduce al compromiso. Por ello, sigo pensando que el mantenimiento de la cláusula cautelar es importante.

La exigencia del respeto del «coto vedado», es decir, la vigencia plena de los derechos vinculados con la satisfacción de las necesidades básicas (o de los bienes primarios) resulta, según javier de lucas, demasiado severa y coloca a la democracia parlamentaria en «el orden de los sueños». Sería un «horizonte normativo» demasiado alto. Algo de razón tiene; posiblemente no exista en la realidad la democracia representativa perfecta. Este es un caso interesante si se lo compara con el de la dictadura perfecta. Mientras que, por ejemplo, alguien podría aducir (recordando casos como el del tratamiento de los obreros extranjeros) que un país de larga tradición democrática como suiza, no es una democracia perfecta y tal vez no encontremos ningún sistema político que pueda ser incluido sin duda alguna en la clase de las democracias perfectas, no nos costaría formular una larga lista de dictaduras perfectas: los nombres de hitler, stalin, pinochet o videla nos ofrecerían una buena guía al respecto. Una explicación plausible de esta asimetría es pensar que las dictaduras pueden ser definidas muy fácilmente recurriendo a una disyunción de condiciones necesarias y suficientes (por ejemplo, persecución de la oposición, violación sistemática de 
los derechos humanos, no observancia del debido proceso legal, etc.): basta que una de estas condiciones sea verdadera para atribuirle el predicado «dictadura perfecta» al sistema político en cuestión. En el caso de la democracia representativa, nos encontramos frente a una conjunción de condiciones necesarias que sólo son suficientes en su conjunto, es decir, la no satisfacción plena de una de ellas hacen surgir dudas acerca de si puede o no aplicarse el rótulo de «democracia representativa perfecta» a un sistema político determinado. Ello no significa que el rótulo sea inútil, sino tan sólo una advertencia en el sentido de que nunca se puede estar plenamente satisfecho con el desarrollo democrático alcanzado. Si el ideal que subyace a la democracia es lograr la completa autodeterminación de cada cual, es comprensible que las «democracias reales» sean siempre un intento de aproximación a este ideal (cfr. Hans Kelsen, General Theory of Law and State, Harvard University Press, Cambridge, Mass., 1949, 288).

b) Javier de Lucas tiene también dudas «acerca del sentido en el que puede hablarse en Kelsen de "derechos fundamentales"». En mi trabajo me he limitado a citar textos de Kelsen relacionados con el tema. Al respecto es bien significativo que en Vom Wesen und Wert der Demokratie (J. C. B. Mohr [Paul Siebeck], Tubinga, 1929, 53) afirme que «[1] la función esencial de los llamados derechos fundamentales y de libertad o derechos humanos y civiles que están garantizados en todas las Constituciones de las democracias parlamentarias modernas es la protección de la minoría». Como Kelsen se refiere a las Constituciones modernas, es de suponer que tenía también en cuenta la Constitución de Weimar. Si se echa una mirada a la misma, no es difícil comprobar que en ella figuraban no sólo derechos de libertad individual (art. 114), de libertad de conciencia y religiosa (arts. 135, 136), inviolabilidad del domicilio (art. 115) y de la correspondencia (art. 117) o libertad de prensa y de expresión (art. 118), sino también derechos tales como el derecho al trabajo (art. 163), o a la asistencia social (art. 119). Es decir, incluía un catálogo bastante completo de candidatos al «coto vedado» en su sentido fuerte. Y hay que tener en cuenta que Kelsen sostenía que si no se respetaban estos derechos, se derrumbaba el principio de la mayoría, fundamento indispensable de la democracia representativa. No es necesario sustentar una posición objetivista en la ética para sostener la necesidad de un «coto vedado»; ello requiere tan sólo proponer, como lo hace Kelsen, admitir una definición de democracia representativa que no admita el dominio de la mayoría y acepte que el «principio de la 
mayoría, y por lo tanto, la idea de la democracia es una síntesis de las ideas de libertad e igualdad». (General Theory of Law and State, 287). La inclusión de la igualdad en la idea de democracia permite también inferir que los derechos fundamentales a los que se refiere Kelsen no se agotan en el derecho a la libre expresión de las ideas. Además, si el objeto de la discusión parlamentaria es la obtención del compromiso y si en ello consiste el «verdadero significado del principio de la mayoría» (cfr. Vom Wesen und Wert der Demokratie, 57) no parece muy desacertado afirmar que las condiciones mismas que hacen posible el compromiso (el respeto del «coto vedado») no pueden, a su vez, ser objeto de negociación y compromiso. No aceptar que tal es el caso implicaría admitir la posibilidad de que las decisiones mayoritarias pudieran en todo momento destruir las bases de la democracia parlamentaria, es decir, implicaría propiciar la dictadura de la mayoría, que es justamente lo que Kelsen desea, con razón, evitar. 